\title{
Assessment of the relative impacts of climate changes and anthropogenic forcing on Ouergha watershed hydrology (North-East of Morocco).
}

\author{
Lamia Erraioui ${ }^{1 *}$, Nouhaila Mafhoum ${ }^{1}$, Soufiane Taia ${ }^{1}$, Jamal Chao ${ }^{1}$, Bouabid El Mansouri ${ }^{1}$, Souad Haida ${ }^{1}$ and Kamal \\ Taj-Eddine ${ }^{2}$ \\ ${ }^{1}$ Laboratory of Geosciences of Natural Resources, Faculty of Sciences Kénitra, Ibn Tofail University, 133 Kénitra, Morocco \\ ${ }^{2}$ Laboratory of Geosciences Semlalia, Faculty of Sciences Semlalia, Cadi Ayyad University, 4000 Marrakech, Morocco
}

\begin{abstract}
Understanding the spatiotemporal distribution of past and future climate change impact is essential for effective water resource management. This study aims to reveal the impact of temperature and precipitation change on hydrological streamflow of Ouergha watershed and on the inflow regime of Al Wahda dam. Initially, historical climate trend was assessed using Mann Kendall tests and Sen's slope. Then, regional Climate Models (Cordex-Africa) were used to project future precipitation and temperature data under two emission scenarios (RCP4.5 as realistic and RCP8.5 as pessimistic). After correcting the biases in climatic variables using three different methods, the calibrated and validated SWAT model was forced to project the hydrological simulations under both scenarios. The study shows a clear decreasing in precipitation and augmentation in annual mean temperature over the past decades. In addition, projected climate variables expected severe change in future precipitation (decreasing) and mean temperature (Increasing). The impact of this climatic alteration is expected to extremely affect rivers discharge and reservoir inflows in both magnitude and timing.
\end{abstract}

\section{Introduction}

Morocco is classified as one of the arid and semi-arid areas, and it is considered to be one of the water-scarce regions $[1,2]$. Thus, the managing and planning of water resources are becoming more challenging because of the uncertainties of climate change. In the future, Morocco is expected to face a major water shortfall prompted by expansion in demand for water, reduction in precipitation induced by climate change, or both. Evidence from historical climatic data suggested some significant trends (upward) in extreme and mean temperature [3]. These climatic changes will extremely affect water availability, including surface water, groundwater and water yield, which subsequently will impact hydrologic flows into streams, lakes and dams [4].

The Ouergha River is the main supplier of the Sebou watershed with about $70 \%$ of the total water yield with a contribution of about $5.6 \mathrm{Mm}^{3} /$ year [5]. Ouergha River is controlled by Al Wahda dam, with a capacity of $3,8 \mathrm{Mm}^{3}$, which makes it an important component in the development of the Gharb plain. It was built in November 1996, to regulate the water supply of the Ouergha river and to prevent the catastrophic effects of floods. The dam irrigates about 100,000 ha in the Gharb and produces nearly an average of 400 million Kwh/year, representing $16 \%$ of total hydropower production in Morocco. It also allows the transfer of approximately $600,106 \mathrm{~m}^{3}$ of water to regions further south [5].

The objective of this study is to investigate future water supplies change in reservoir by studying the impact of past and future temperature and precipitation change on hydrological processes of Ouergha catchment as well as on the inflow to Al Wahda Dam. The most common approach for hydrological impact studies of climate change is to run hydrological models with climate scenarios, usually provided by the outputs of precipitation and temperature from downscaled climate models, to the catchment of interest $[6,7,8,9]$. Thus, Soil and Water Assessment Tools (SWAT), calibrated and validated over Ouergha watershed in previous work [10], was used in this study. This model enables to simulate the spatial and temporal hydrological processes in the catchment. Precipitation and temperature from the outputs of regional climate models were used to force hydrological models, which then allow streamflow simulations to be carried out. Nevertheless, outputs from climate models in the control period do not usually fit exactly the statistical properties of observations at gauging stations in the same period [11]. Bias errors between climate models and observations can be caused by a limited conceptualisation or spatial averaging within grid cells [12]. However, bias correction methods such as power transformation, linear scale, distribution mapping and variant scaling were used to reduce the bias in daily maximum and minimum temperature and daily precipitation before their application in hydrological model [13].

\footnotetext{
*Corresponding author: lamia.er-raioui@uit.ac.ma
} 


\section{Materials and methods}

\subsection{Data pre-processing and study area}

The Ouergha catchment is located in northern Morocco and it covers an area of around $7300 \mathrm{~km}^{2}$ which represents about $18.2 \%$ of the Sebou basin of which it is part [14]. It is controlled by Al Wahda dam. Which is mainly used for water regulation, flood protection and hydropower production. It is $19 \mathrm{~km}$ long and has a full impoundment volume of $3.800 \mathrm{Mm}^{3}$ (figure 1).

The rainfall input data for the Ouergha basin were provided by the Hydraulic Basin Agency of Sebou (ABHS). The rainfall gauges managed by the ABHS have provided us with a large amount of rainfall data at daily, monthly and yearly time step. The concerned stations are Galez, Jbel Outka, Tabouda, Bab Ouender, Ain Aicha, Al Wahda, Khenichet and M'jaara. The study period, which goes on from 1970 to 2014, was chosen by crossing the observation period of the different stations and according to the availability of daily precipitation data. However, these data almost hold gaps that prevent their direct use and require pre-processing beforehand. Statistical regression with neighbour gauges has been used to fill the gaps in precipitation time series. Maximum and minimum daily temperatures are provided by the climatological forecasting system called CFSR (Climate Forecast System Reanalysis).

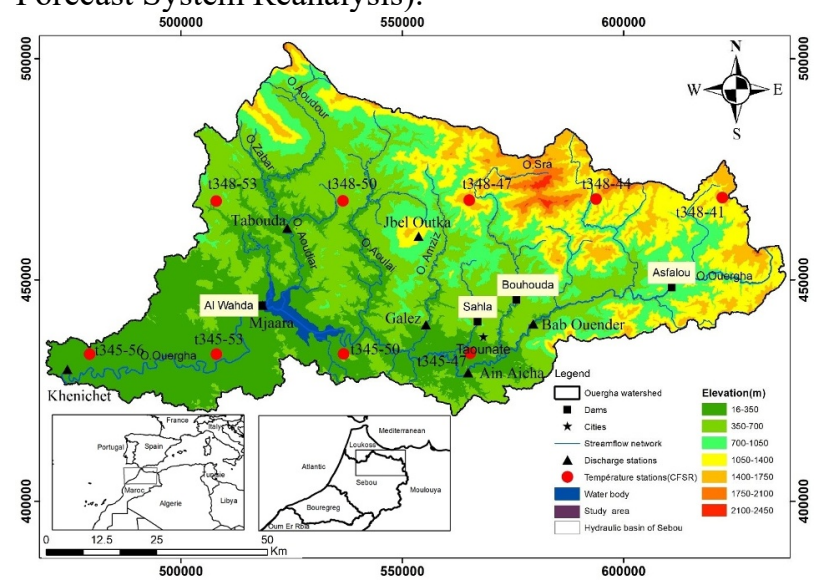

Fig. 1. Map of Ouergha watershed and data gage's location

\subsection{Trend analysis}

In this paper, two non-parametric techniques (MannKendall and Sen's slope) were used to estimate the trends in precipitation and temperature data.

The non-parametric Mann Kendall trend test is widely used to assess the significance of monotonic trends in hydro-meteorological time series in order to determine increasing or decreasing expressions. Its principle is based on checking the significance of trends using the correlation between the ranks of a time series and their order [15].

The Sen's slope (also called Theil - Sen Estimator) is a nonparametric test developed by [16] and which is an extension of the Wetensch test. This test estimates both the magnitude of the linear trend (i.e., the linear rate of change) and confidence levels [17]. It is considered to be an extremely less sensitive test to missing data and outliers. This makes it a more robust method than the least squares estimator [15].

\subsection{Climate change scenarios}

In order to evaluate future climate projections in the study site, dynamically downscaled output data from the French Global Climate Model CNRM-CM5 (used in the 5th version of the Coupled Model Intercomparison Project (CMIP5)), were used. Data for this model was derived from CORDEX-Africa domain at $12.5 \mathrm{~km}$ horizontal resolution. Two Representative Concentration Pathways (RCPs) were selected, RCP4.5 as a realistic emission scenario and RCP8.5 as the pessimistic one [18].

However, climate models often provide biased representations of observed times series due to systematic model errors caused by imperfect conceptualisation, discretisation and spatial averaging within grid cells. Thus, application of bias-correction methods is recommended [13]. Bias correction is generally used to minimise discrepancy and uncertainty between observed and simulated climate variables using empirical relationships between large-scale features and local conditions assuming that these relations stay the same in changing climate [19]. In this study, several techniques have been used to adjust the biases in RCMs outputs. The precipitation correction methods involve linear scaling (LS), distribution mapping (DM) and power transformation (PT). For the temperature LS, DM, and variance scaling (VS) were used. Further details on the procedures and equations of each method could be found in [20].

Before the bias corrected data are used to conduct hydrological analysis, the performance of bias correction methods was exanimated in order to evaluate the capacity of the participating models in reproducing regional temperature and precipitation. As the historical time series from CMIP5 projects are generally from 1950 to 2005, as well as the predicted scenarios from 2006 to 2050. In this study we used the period from 1970 to 2000 to optimize the model parameters and the period from 2000 to 2005 to validate the models for eventual selecting either of the methods would give us the most accurate results. Thus, the performance of the models is evaluated through three statistical indices: the Nash-Sutcliffe efficiency (NSE), the determination coefficient $\left(\mathrm{R}^{2}\right)$ and the root-meansquare-error (RSME).

\subsection{Hydrological model}

In this study the Soil and Water Assessment Tool (SWAT) was used to simulate hydrological process in the Ouergha watershed. SWAT is a semi-distributed, continuous-time, process-based hydrology and water quality model. SWAT uses a daily time step and hydrological response units to simulate various ecohydrological and anthropogenic processes within the study area. The model has been used widely for simulating snow, standing water, crop growth, and water quality. 
The model was calibrated and validated over the basin in previous works $[10,14]$. The SWAT model of the basin was obtained after a calibration-validation and a detailed sensitivity analysis processes that allows converging to the best SWAT model in terms of efficiency. According to [10], the SWAT model was able to simulate streamflow in Ouergha watershed with performances between 0.62 and 0.85 of NSE. Indeed, the model correctly reproduces the streamflow over the period from 1990 to 2014 and this on almost all the stations considered in the calibration. However, the bias corrected future data were used to force SWAT model, which then allows water balance components to be simulated in a monthly time scale.

\section{Results and discussions}

\subsection{Trends analysis}

In this study trend analysis method was applied to annual rainfall over the eight rainfall gauges for the period of 45 years (1970-2014). It was revealed from the results that the amount of rainfall is decreasing. As illustrated, the Ouergha watershed shows negative trends all over the catchment. The figure 2 shows an exception in the south center area with positive trend of about $+0.96 \mathrm{~mm} /$ year. The most negative trends are found in the western part of the catchment, exactly upstream of Al Wahda dam. While the eastern part of the basin has marked relatively small negative trends.

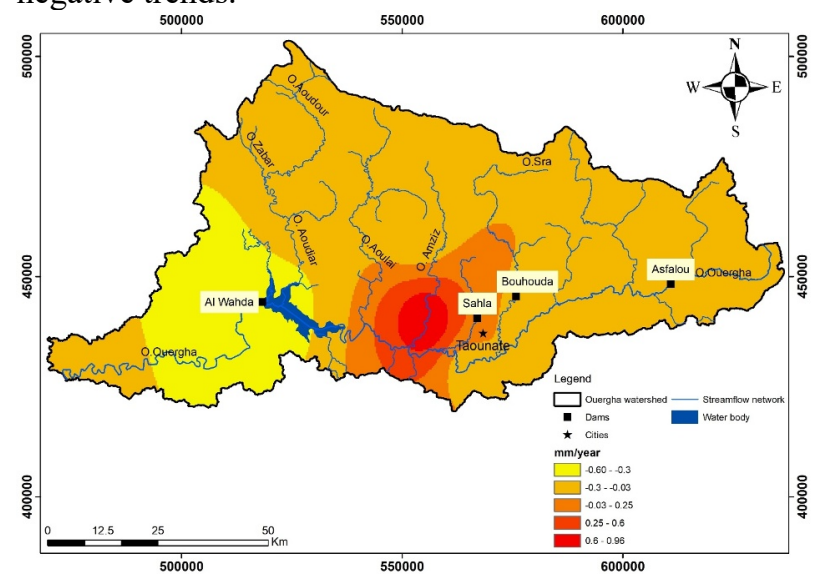

Fig. 2. Spatial distribution of trends by Sen's slope method in annual rainfall for the period (1970-2014).

Table 2. Mann-Kendall and Sen's slope analysis of annual rainfall data.

\begin{tabular}{|c|c|c|c|}
\hline Station & P-value & Son Slope & Trend \\
\hline Ain Aicha & 0.008 & -0.607 & Decreasing \\
\hline Bab Ouender & 0.034 & -0.505 & Decreasing \\
\hline Galez & 0.021 & -0.292 & Decreasing \\
\hline Jbel Outka & 0.050 & 0.969 & Increasing \\
\hline Khenichet & 0.373 & -0.173 & - \\
\hline Mjaara & 0.041 & -0.172 & Decreasing \\
\hline Tabouda & 0.475 & -0.14 & - \\
\hline Al Wahda & 0.538 & -0.16 & - \\
\hline
\end{tabular}

Table 2 represents the Mann Kendall test and Sen's slope of the 8 stations. The trends in precipitation were significant with a p-value of $0.008,0.034$ and 0.05 for Ain Aicha, Bab Ouender and Jbel Outka respectively.
However, these results are consistent with previous study, [21] reported a slight significant downward trend in the Gharb region with a slope of around $-0.01 \mathrm{~mm} /$ year. Furthermore, [22] observed a decreasing trend in the summer, although not significant in the two basins of Bouregreg and Tensift.

For the mean temperature, figure 3 shows the spatial variation of trends by Sen's slope. Increasing trends in annual mean values (from $+0.002^{\circ} \mathrm{C} /$ year to $+0.035^{\circ} \mathrm{C} /$ year) were detected for most of the used stations. Indicating positive trends in temperature in the north, east, and center of the basin. The upstream of $\mathrm{Al}$ Wahda Dam were marked by negative trends of about $-0.008^{\circ} \mathrm{C} /$ year.

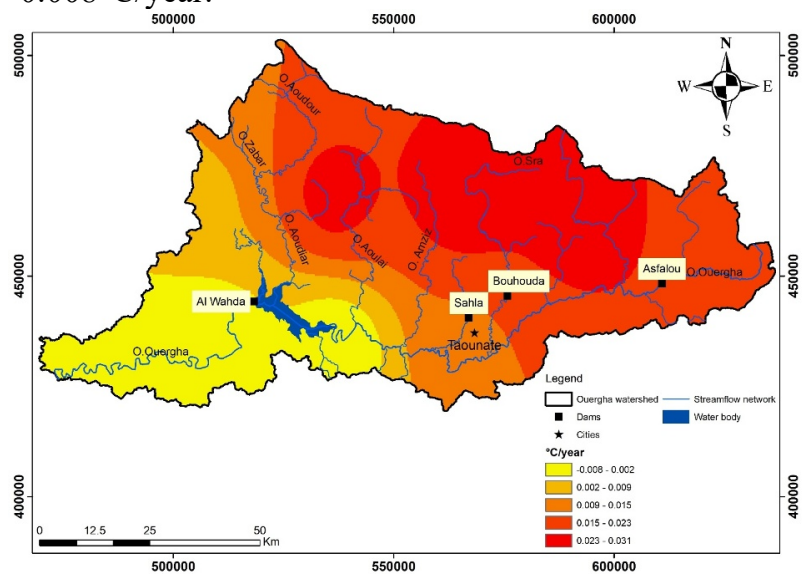

Fig. 3. Spatial distribution of trends by Sen's slope method in annual mean temperature for the period (1979-2014).

Table 3. Mann-Kendall and Sen's slope analysis of annual temperature data.

\begin{tabular}{|c|c|c|c|c|c|c|}
\hline \multirow{2}{*}{$\begin{array}{c}\text { Station } \\
\text { name }\end{array}$} & \multicolumn{2}{|c|}{$\begin{array}{c}\text { Mean } \\
\text { temperature }\end{array}$} & \multicolumn{2}{c|}{$\begin{array}{c}\text { Maximum } \\
\text { temperature }\end{array}$} & \multicolumn{2}{c|}{$\begin{array}{c}\text { Minimum } \\
\text { temperature }\end{array}$} \\
\cline { 2 - 7 } & $\begin{array}{c}\text { p- } \\
\text { value }\end{array}$ & $\begin{array}{c}\text { Sen's } \\
\text { slope }\end{array}$ & $\begin{array}{c}\mathrm{p}- \\
\text { value }\end{array}$ & $\begin{array}{c}\text { Sen's } \\
\text { slope }\end{array}$ & $\begin{array}{c}\mathrm{p}- \\
\text { value }\end{array}$ & $\begin{array}{c}\text { Sen's } \\
\text { slope }\end{array}$ \\
\hline $\mathrm{t} 345 \_47$ & 0.258 & 0.008 & 0.470 & -0.010 & 0.012 & 0.028 \\
\hline $\mathrm{t} 345 \_50$ & 0.653 & -0.006 & 0.693 & -0.008 & 0.859 & 0.002 \\
\hline $\mathrm{t} 345 \_53$ & 0.051 & 0.023 & 0.040 & 0.033 & 0.042 & 0.022 \\
\hline $\mathrm{t} 345 \_56$ & 0.153 & 0.011 & 0.205 & 0.021 & 0.124 & 0.013 \\
\hline $\mathrm{t} 348 \_41$ & 0.018 & 0.028 & 0.035 & 0.045 & 0.032 & 0.022 \\
\hline $\mathrm{t} 348 \_44$ & 0.008 & 0.028 & 0.013 & 0.043 & 0.023 & 0.025 \\
\hline $\mathrm{t} 348 \_47$ & 0.070 & 0.016 & 0.117 & 0.022 & 0.169 & 0.014 \\
\hline $\mathrm{t} 348 \_50$ & 0.595 & -0.005 & 0.236 & -0.025 & 0.002 & 0.035 \\
\hline $\mathrm{t} 348 \_53$ & 0.733 & -0.002 & 0.117 & -0.029 & 0.005 & 0.035 \\
\hline $\mathrm{t} 345 \_47$ & 0.577 & -0.005 & 0.186 & -0.021 & 0.713 & 0.005 \\
\hline
\end{tabular}

It's also observed that all the stations have positive trends for maximum, minimum and mean temperature. The strongest trends were recorded for maximum temperatures with high levels of significance $(\mathrm{p}$-value $=$ $0.013^{\circ} \mathrm{C} /$ year) at stations t345_53, t348_41 and t348_44. Regarding minimum temperatures, the positive trends were observed in 5 stations ( $\mathrm{t} 345 \_47, \mathrm{t} 345$ 53, t $348 \_41$, t348 44, t348 50 and t348 53), with higher level of significance $(\bar{p}$-value $<0.0 \overline{5})$. Stations t348_41 and t348_44 were the only ones to have recorded a small trend of increase in mean temperatures with respectively a $p$ value of 0.008 to 0.018 levels of significance (Table 3 ). These trend results agree very much with those of previous work conducted by [1] who observed, across Morocco, an annual increase in average temperatures of +0.01 to $+0.04{ }^{\circ} \mathrm{C} /$ year [1]. 


\subsection{Future climate change scenarios}

\subsubsection{Evaluation of performance of bias correction methods.}

The performance of each bias correction method is evaluated based on the calculation of the statistical parameters between observed and historical RCM for the period of 2000-2005. From the results of table 4, we could notice that all bias correction methods were able to effectively improve the original RCM simulations (Raw). The methods LS and DM shows more accuracy and performance for all precipitation stations compared to PT method, which lead us to choose one of the two methods for future bias correction of RCM outputs. In addition, based on the RMSE it can be seen that the LS method is the best for precipitation data. Furthermore, several studies have confirmed that the best bias correction method for precipitation is the linear scaling (LS) $[23,24,25]$.

Table 4: Time-series-based metrics of original and corrected precipitation at the discharge's stations

\begin{tabular}{|c|c|c|c|c|}
\hline Station & Methods & NSE & $\mathrm{R}^{2}$ & RMSE \\
\hline \multirow{4}{*}{ Ain Aicha } & Raw & 0.30 & 0.36 & 8.58 \\
\hline & LS & 0.49 & 0.47 & 8.00 \\
\hline & DM & 0.45 & 0.47 & 8.02 \\
\hline & PT & 0.26 & 0.34 & 8.62 \\
\hline \multirow{4}{*}{ Bab Ouender } & Raw & 0.20 & 0.32 & 8.92 \\
\hline & LS & 0.49 & 0.50 & 8.00 \\
\hline & DM & 0.49 & 0.50 & 8.03 \\
\hline & PT & 0.31 & 0.36 & 8.74 \\
\hline \multirow{4}{*}{ Galez } & Raw & 0.30 & 0.36 & 8.77 \\
\hline & LS & 0.50 & 0.50 & 8.00 \\
\hline & DM & 0.50 & 0.50 & 8.03 \\
\hline & PT & 0.41 & 0.42 & 8.53 \\
\hline \multirow{4}{*}{ Jbel Outka } & Raw & 0.20 & 0.32 & 10.00 \\
\hline & LS & 0.50 & 0.50 & 8.00 \\
\hline & DM & 0.49 & 0.50 & 8.10 \\
\hline & PT & 0.49 & 0.49 & 8.44 \\
\hline \multirow{4}{*}{ Khenichet } & Raw & 0.30 & 0.35 & 8.63 \\
\hline & LS & 0.50 & 0.49 & 8.00 \\
\hline & DM & 0.50 & 0.50 & 8.09 \\
\hline & PT & 0.45 & 0.46 & 8.30 \\
\hline \multirow{4}{*}{ Mjaara } & Raw & 0.31 & 0.36 & 8.70 \\
\hline & LS & 0.50 & 0.50 & 8.00 \\
\hline & DM & 0.50 & 0.50 & 8.06 \\
\hline & PT & 0.45 & 0.46 & 8.34 \\
\hline \multirow{4}{*}{ Tabouda } & Raw & -0.35 & 0.19 & 9.53 \\
\hline & LS & 0.50 & 0.50 & 8.00 \\
\hline & DM & 0.49 & 0.50 & 8.04 \\
\hline & PT & 0.45 & 0.45 & 8.38 \\
\hline \multirow{4}{*}{ Al Wahda } & Raw & -0.80 & 0.14 & 9.53 \\
\hline & LS & 0.50 & 0.50 & 8.00 \\
\hline & DM & 0.50 & 0.50 & 8.04 \\
\hline & PT & 0.46 & 0.46 & 8.31 \\
\hline
\end{tabular}

For the temperature bias correction performance analysis, the results also confirm that all the methods reduce the bias in the original RCM (table 5). The performances were quite similar for all methods. Despite, VS is relatively better than the two other methods LS and DM. Finally, from this comparison we have selected LS for precipitation and VS for temperature.
Table 5: Time-series-based metrics of original and corrected temperature in the stations

\begin{tabular}{|c|c|c|c|c|}
\hline Station & Methods & NSE & $\mathrm{R}^{2}$ & RMSE \\
\hline \multirow{4}{*}{$\mathrm{t} 345 \_47$} & Raw & 0.55 & 0.69 & 5.23 \\
\hline & $\mathrm{LS}$ & 0.56 & 0.69 & 5.17 \\
\hline & DM & 0.54 & 0.68 & 5.32 \\
\hline & VS & 0.54 & 0.68 & 5.31 \\
\hline \multirow{4}{*}{ t345_50 } & Raw & 0.50 & 0.67 & 5.44 \\
\hline & LS & 0.55 & 0.69 & 5.17 \\
\hline & DM & 0.52 & 0.68 & 5.32 \\
\hline & VS & 0.52 & 0.68 & 5.31 \\
\hline \multirow{4}{*}{ t345_53 } & Raw & 0.53 & 0.68 & 5.10 \\
\hline & $\mathrm{LS}$ & 0.54 & 0.68 & 5.03 \\
\hline & DM & 0.51 & 0.67 & 5.20 \\
\hline & VS & 0.52 & 0.68 & 5.19 \\
\hline \multirow{4}{*}{ t345_56 } & Raw & 0.52 & 0.68 & 4.86 \\
\hline & $\mathrm{LS}$ & 0.54 & 0.68 & 4.76 \\
\hline & DM & 0.51 & 0.67 & 4.91 \\
\hline & VS & 0.51 & 0.68 & 4.91 \\
\hline \multirow{4}{*}{$\mathrm{t} 348 \_41$} & Raw & 0.54 & 0.68 & 4.95 \\
\hline & LS & 0.62 & 0.72 & 4.47 \\
\hline & DM & 0.62 & 0.72 & 4.49 \\
\hline & VS & 0.63 & 0.73 & 4.45 \\
\hline \multirow{4}{*}{ t348_44 } & Raw & 0.57 & 0.70 & 4.82 \\
\hline & $\mathrm{LS}$ & 0.63 & 0.73 & 4.50 \\
\hline & $\mathrm{DM}$ & 0.60 & 0.71 & 4.67 \\
\hline & $\mathrm{VS}$ & 0.61 & 0.72 & 4.64 \\
\hline \multirow{4}{*}{$\mathrm{t} 348 \_47$} & Raw & 0.53 & 0.68 & 4.93 \\
\hline & $\mathrm{LS}$ & 0.60 & 0.71 & 4.60 \\
\hline & DM & 0.55 & 0.69 & 4.84 \\
\hline & $\mathrm{VS}$ & 0.55 & 0.69 & 4.83 \\
\hline \multirow{4}{*}{ t348_50 } & Raw & 0.55 & 0.69 & 4.78 \\
\hline & $\mathrm{LS}$ & 0.57 & 0.70 & 4.70 \\
\hline & DM & 0.52 & 0.68 & 4.99 \\
\hline & VS & 0.52 & 0.68 & 4.99 \\
\hline \multirow{4}{*}{ t348_53 } & Raw & 0.51 & 0.67 & 4.91 \\
\hline & $\mathrm{LS}$ & 0.55 & 0.69 & 4.73 \\
\hline & DM & 0.49 & 0.68 & 5.06 \\
\hline & $\mathrm{VS}$ & 0.49 & 0.68 & 5.06 \\
\hline
\end{tabular}

\subsubsection{Climate change scenarios}

Figure 4 shows the projected monthly averaged precipitation from bias corrected climate model with two RCP scenarios for the future period (2022-2050), compared to the baseline period (1985-2013). The results show that all the climate simulations lead to a decrease in precipitation. This decrease appears particularly marked during December and February. The projected changes in precipitation are $-53.38 \mathrm{~mm}$ (in December) in the RCP4.5 scenario and -46.17 (in December) for the RCP8.5 scenario.

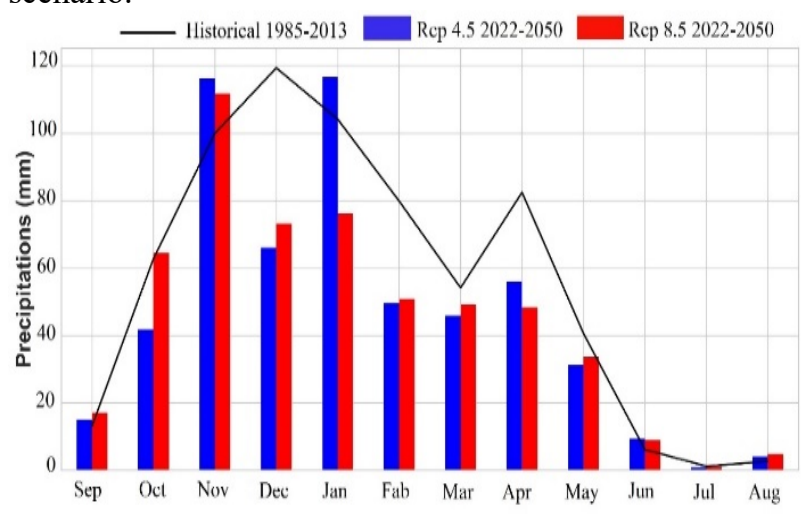

Fig. 4: Change in average monthly precipitation 
The RCP4.5 is marked by two important increases in November and January with a large exceed of the reference. For the RCP8.5 scenario, the average precipitation follows a particular profile with a gradual increase in autumn marked by a larger peak in November. In the spatial characteristic of projected precipitation (figure 5 and 6), a significant decrease under both scenarios dominates all the part of the basin. These reductions have been less critical in the Jbel Outka and around the lake of Al Wahda dam. While the most affected area was observed in the downstream and the south part of the Ouergha Watershed, thus, the relative variation of rainfall reached $-24 \%$ under RCP4.5 and $26 \%$ under RCP8.5. We note the distribution of relative changes of rainfall all around the watershed is very similar under the two scenarios.

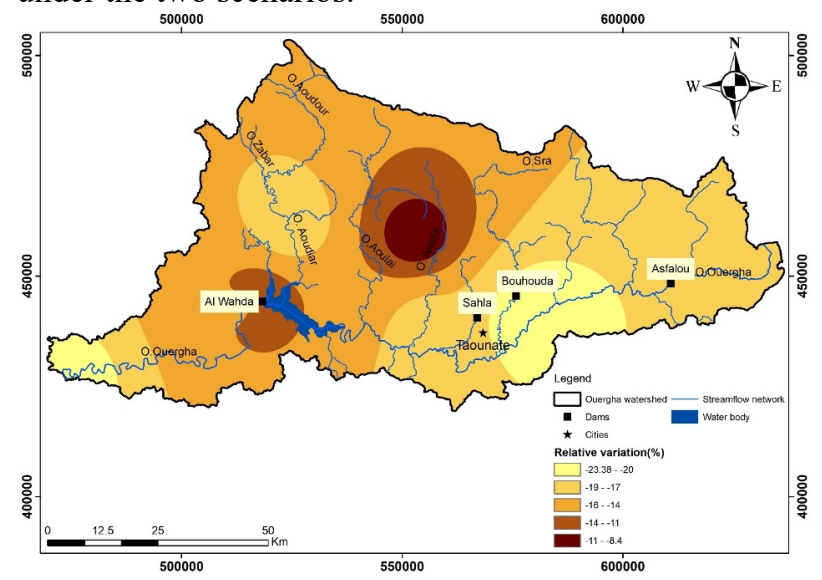

Fig. 5: Change of yearly mean precipitation under RCP4.5 in future period (2022-2050) relative to the baseline period (19852013)

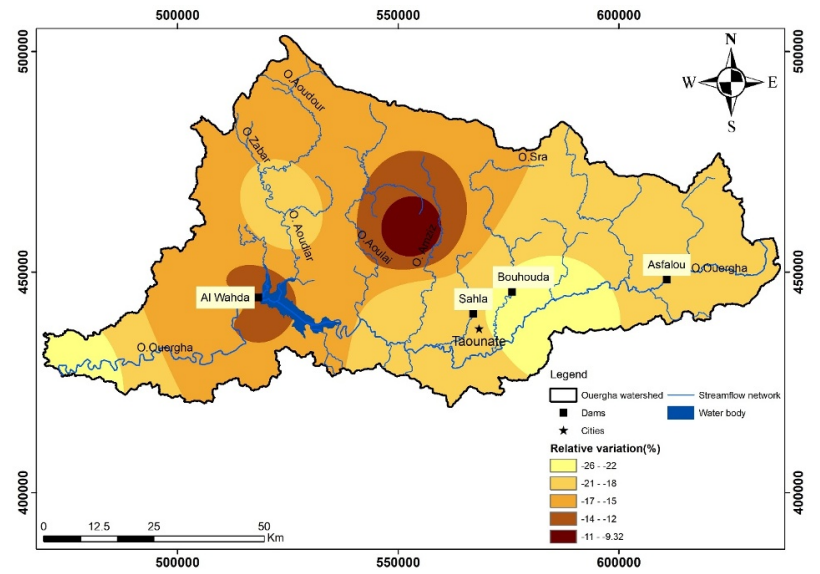

Fig. 6: Change of yearly mean precipitation under RCP8.5 in future period (2022-2050) relative to the baseline period (19852013)

For the mean temperatures, it can be seen that both scenarios suggest a significant increase in temperature (figure 7), with deviations ranging from $+0.14{ }^{\circ} \mathrm{C}$ (April) to $+2.18^{\circ} \mathrm{C}$ (June) for the RCP4.5. For the RCP8.5 scenario the deviation varies from $+0.76^{\circ} \mathrm{C}$ (December) to $+1.78^{\circ} \mathrm{C}$ (May). A high rise is marked during the months from June to September. The driest month is August while the coldest month is January for all the resorts.

The mean temperature over the catchment marked by an increasing trend under both climate scenarios in all parts of the basin (Figure 8 and 9). However, according to the scenario RCP4.5, all the surrounding areas upstream of

Al Wahda reservoir and the east region of Ouergha basin have a lower increasing rate comparing to the downstream part of the basin. Similarly, the increasing trend in temperature is expected all over the region under RCP4.5, but at a higher rate in the Nord-west region compared to the middle hills and downstream areas.

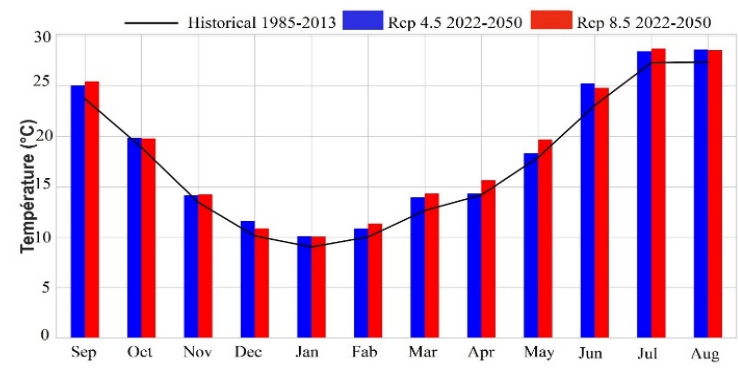

Fig. 7: Change in average monthly temperature

Due to most likely increase in average temperature in both scenarios, it is necessary to plan on optimising water usage for the irrigation area of the region. These results are in agreement with previous study conducted by [26], the analysis expected a strong increase of mean temperatures of about $+1.3^{\circ} \mathrm{C}$ and $+1.44^{\circ} \mathrm{C}$ under RCP 4.5 and RCP8.5, respectively.

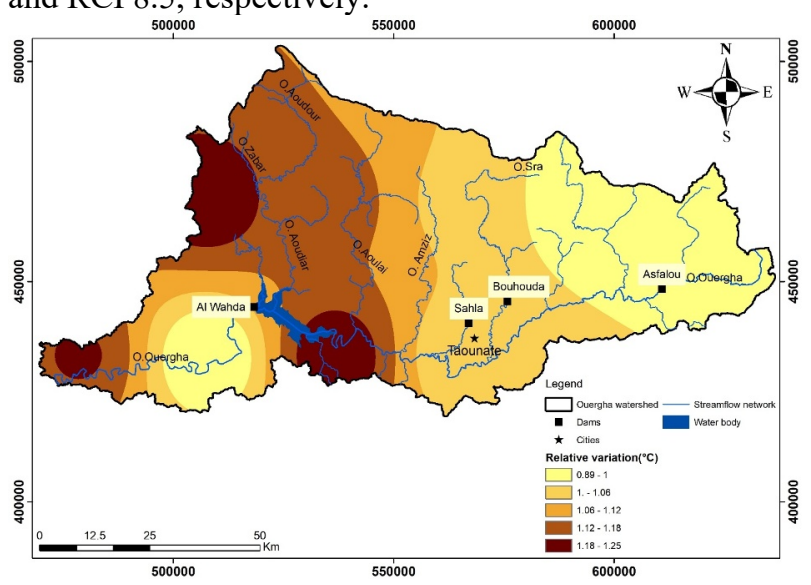

Fig. 8: Change of yearly mean temperature under RCP4.5 in future period (2022-2050) relative to the baseline period (19852013)

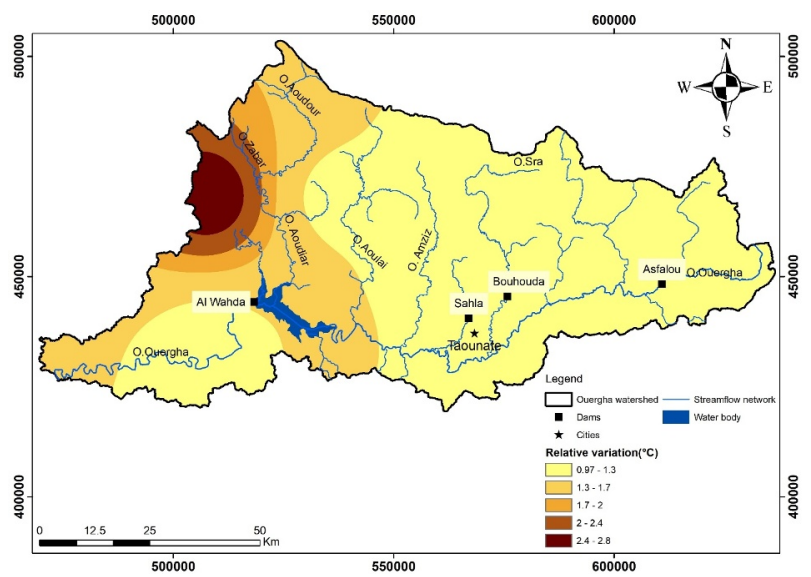

Fig. 9: Change of yearly mean temperature under RCP8.5 in future period (2022-2050) relative to the baseline period (19852013) 

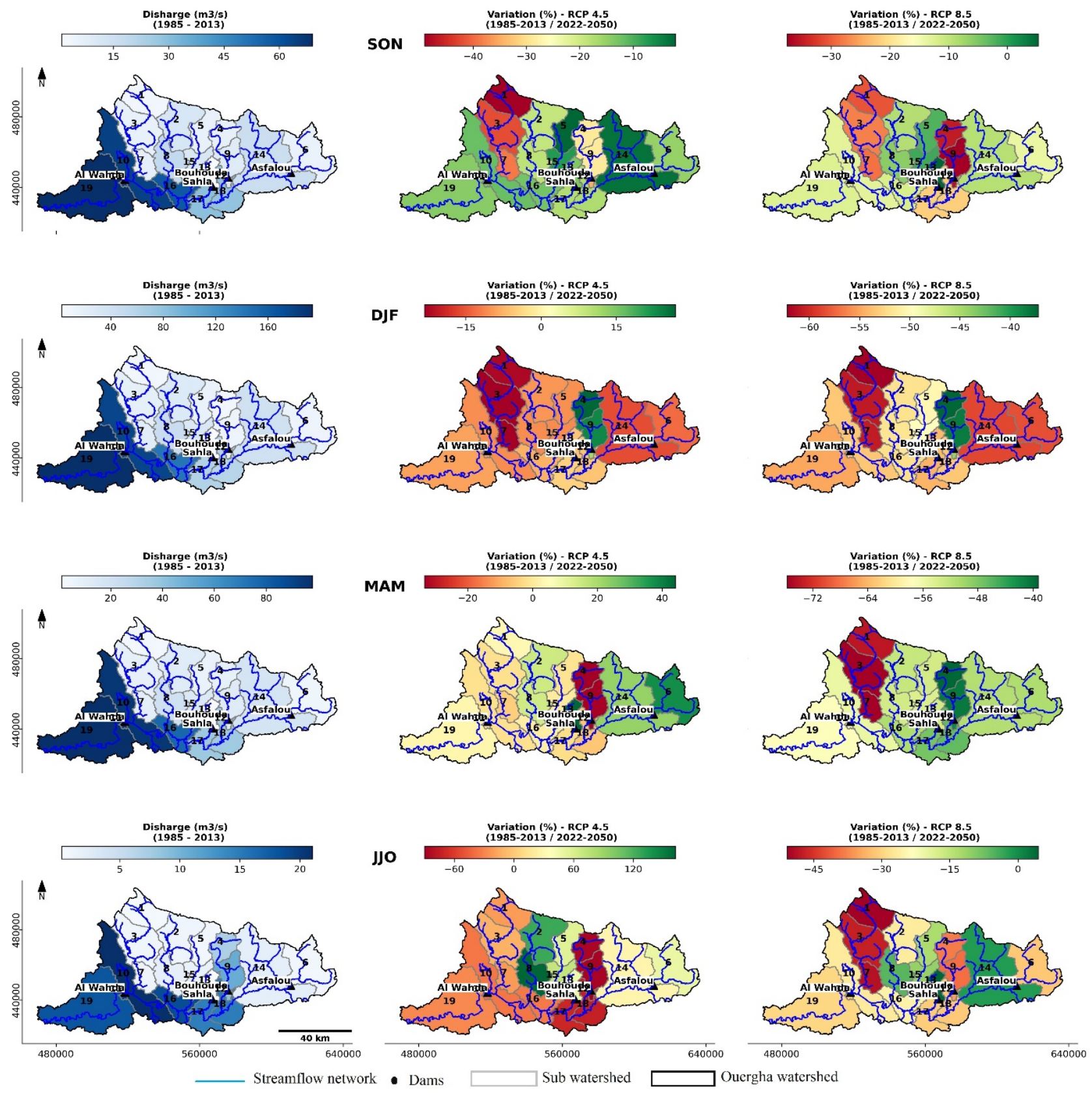

Fig. 10: Evolution of discharge of Ouergha Watershed. Evolution between the reference period 1985-2013 and the future period 2022-2050, under two scenarios RCP4.5 and RCP8.5. (SON: September, October, November; DJF : December, January, February; MAM : March, Avril, May and JJA : June, July, August).

\subsection{Impact of climate change on hydrological process of Ouergha Watershed}

\subsubsection{Impact of climate change on Ouergha discharges}

The climate change scenarios (projected precipitation and temperature) are inserted to the hydrological model. The computed projections of discharge in future are compared with the baseline to illustrate the relative variation for both scenarios RCP4.5 and RCP8.5. The results show that the impact of climate change scenarios leads to consistent relative variation in all seasons under both scenarios (Figure 10). However, it is observed that discharges in autumn (SON) are decreasing in all parts of the watershed under both scenarios with a rate of $-40 \%$ detected in the attribute of Oued Aoudour and $-30 \%$ noticed in Oued Sra under the RCP4.5 and RCP8.5 respectively. In winter the scenario RCP8.5 has reached a variation of $-60 \%$ detected in Oued Aoudour. While an increase variation observed in Oued Sra for the same season under RCP4.5. The highest rate of change was observed in spring (MAM) under the scenario RCP8.5 in all subbasins. In contrast, a relative increase was detected downstream of Oued Ouergha in same season under RCP4.5. For the summer a decreasing in the discharges is projected for all Ouergha catchment under the scenario RCP8.5. Instead, the rate of change under RCP4.5 is negative at Oued Sra and positive at Oued Aoulai. 


\subsubsection{Impact of climate change on reservoir inflow}

Figure 11 displays the changes of future monthly inflow to Al Wahda reservoir. A wide range of inflow change in different months and under the two scenarios is anticipated. The inflows of Al Wahda dam under scenario RCP4.5 seem to increase in November, January, February, Avril, May and June. Changes under RCP8.5 were more aggressive in comparison to these resulted from RCP4.5. December is the most affected by these changes under all scenarios. It is observed that a downward trend of inflow in all months under RCP8.5, the amount of water entering the reservoir will decrease from September to August. In parallel of the decreasing of water supply to Al Wahda Dam, the temporal distribution are expected to prolong. As the peak observed in December in the historical regime is moved to November and January under RCP 8.5 and RCP4.5, respectively. This result is consistent with the work of [27], which assumes that in addition to the reduction of the volume of water supply, the projected variation has prolonged temporally compared to the historical regime.

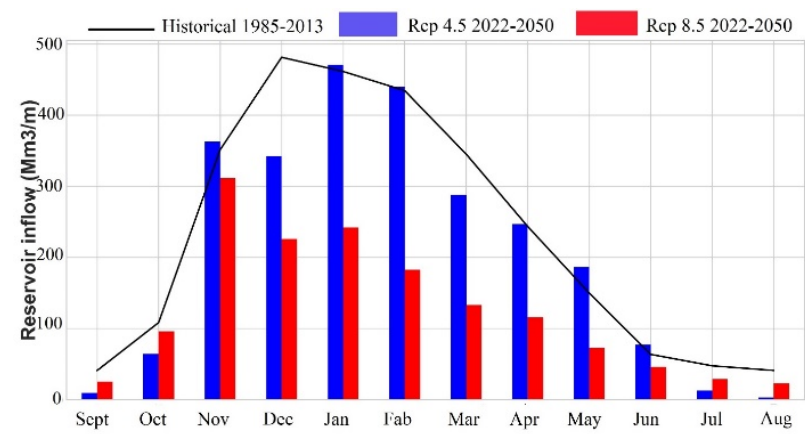

Fig. 11: Evolution of monthly inflows to Al Wahda dam between the reference period (1985-2013) and the future period (2022-2050). Under two scenarios (RCP4.5 and RCP8.5)

\section{Conclusion}

This study investigated the possible changes in rainfall patterns over Ouergha watershed, based on a detailed statistical analysis of historical daily rainfall records available at 8 stations, and daily temperature of 10 stations from CFSR. A non-parametric test of Mann Kendall and Sen's slope were realised over the historical data to detect possible trends in the climatic variables. To assess the future climate change, a typical top-down climate change assessment procedure was followed including the use of realistic and pessimistic emissions scenarios. The climate projections data used were from the CRNM-CM5 simulations over Cordex-Africa domain. The model outputs are bias-corrected using three statistical approaches. Once the projection of climate variable was done, the use of the projected variables is used to force SWAT model in order to assess the impact of climate change on Ouergha rivers discharge and on the inflow to Al Wahda dam. The result predicts a temperature rise ranging from $2.18^{\circ} \mathrm{C}$ in June under the RCP4.5 and $1.78^{\circ} \mathrm{C}$ in May under the RCP8.5. As well as, a remarkable reduction in precipitation predicted to reach $53.38 \mathrm{~mm}$ and $-46.17 \mathrm{~mm}$ in December under RCP4.5 and
RCP8.5, respectively. However, an increase in precipitation would be observed in November compared to the reference period (1985-2013), which considerably affect the water resources in the watershed. The rates of variation of the discharge were relatively high. The climate change impacts the water resource of Ouergha watershed in different levels. The spatial variation of the change rate is extremely observed during all season and all over the study areas. The water supply to Al Wahda dam not only predicted to decrease but also its seasonal regime is affected under both scenarios.

\section{References}

1. F. Driouech, M. Déqué, E. Sánchez-Gómez, Weather regimes-Moroccan precipitation link in a regional climate change simulation, Glob. Planet. Change, 10 (2010).

2. M. Al-Saidi, D. Birnbaum, R. Buriti, E. Diek, C. Hasselbring, A. Jimenez, D. Woinowski, Water Resources Vulnerability Assessment of MENA Countries Considering Energy and Virtual Water Interactions, Procedia. Eng, 145, 900-907 (2016).

3. F. Driouech, H. Stafi, A. Khouakhi, S. Moutia, W. Badi, K. ElRhaz, A. Chehbouni, Recent observed country-wide climate trends in Morocco, Int. J. Climatol, 20 (2020)

4. J. Stagl, E. Mayr , H. Koch, F.F. Hattermann, S. Huang, Effects of Climate Change on the Hydrological Cycle in Central and Eastern Europe. In: Rannow S., Neubert M. (eds) Managing Protected Areas in Central and Eastern Europe Under Climate Change. Advances in Global Change Research, vol 58, Springer, Dordrecht (2014)

5. ABHS 2008 : Plan directeur des aménagements intégrés des ressources en eau. Document de synthèse.

6. H.J. Fowler, S. Blenkinsopa, C. Tebaldib, Linking climate change modelling to impacts studies: recent advances in downscaling techniques for hydrological modelling, Int. J. Climatol, 27 (2007)

7. F.H.S. Chiew, J. Teng, J. Vaze, D.A. Post, J.M. Perraud, D.G.C. Kirono, N.R. Viney, Estimating climate change impact on runoff across southeast Australia: Method, results, and implications of the modeling method, Water. Resour. Res, VOL45, W10414(2009)

8. L. Senatore, A. Baldauf, M. Zaldarriagaf, U. Seljak, M. Zaldarriagaf, Galaxy bias and non-linear structure formation in general relativity, J. Cosmol. Astropart. Phys (2011)

9. D. Ruelland, S. Ardoin-Bardin, L. Collet, and P. Roucou: Simulating future trends in hydrological regime of a large Sudano Sahelian catchment under climate change, J. Hydrol., 424-425, 207-216, (2012)

10. L. Erraioui, S. Taia, S. Haida, B. Elmansouri, J. Chao, S. Mrabet, K. Taj-Eddine, Semi-Distributed Modeling Of A Large Scale Hydrological System Using SWAT Model IEEE 2nd ICECOCS 1-6, (2020). 
11. T. Ozturk, M.T. Turp, M. Türkeş, M.L. Kurnaz, Future projections of temperature and precipitation climatology for CORDEX-MENA domain using RegCM4.4, Atmos. Res, 206 (2018)

12. C. Teutschbein, J. Seibert, Bias correction of regional climate model simulations for hydrological climatechange impact studies: Review and evaluation of different methods, J. Hydro. 12 ,29 (2012)

13. C. Teutschbein, T. Grabs, H. Laudon, R. H. Karlsen \& K. Bishop, Simulating streamflow in ungauged basins under a changing climate: The importance of landscape characteristics. J of Hydro., 561, 160-178 (2018)

14. S. Taia, L. Erraioui, N. Claire Mbrenga, J. Chao, B. El Mansouri, S. Haida, K. Taj-Eddine, Assessment of soil erosion using two spatial approaches: RUSLE and SWAT Model, E3S Web of Conferences, 234, 00082 (2021)

15. M. Gocic, S. Trajkovic, Analysis of changes in meteorological variables using Mann-Kendall and Sen's slope estimator statistical tests in Serbia, Glob. Planet. Change, 100, 172-182 (2013)

16. P.K. Sen, Estimates of the regression coefficient based on kendall's tau, J. Am. Stat. Assoc, 63 (1968)

17. T. Pohlert, Non-parametric trend tests and changepoint detection. R Package Version 1.0.0 (2017)

18. M. Musie, S. Sen, P. Srivastava, (2020) Application of CORDEX-AFRICA and NEX-GDDP datasets for hydrologic projections under climate change in Lake Ziway sub-basin, Ethiopia, J. Hydrol, Regional Studies, 31 (2020)

19. C. Piani, G.P. Weedon, M. Best, S.M. Gomes, P. Viterbo, S. Hagemann, J.O. Haerter, Statistical bias correction of global simulated daily precipitation and temperature for the application of hydrological models, J. Hydrol ,395,199,215 (2009)

20. M., Luo, T. Liu, F. Meng, Y. Duan, A. Frankl, A. Bao, P. De Maeyer, Comparing Bias Correction Methods Used in Downscaling Precipitation and Temperature from Regional Climate Models: A Case Study from the Kaidu River Basin in Western China. Water, 10, 1046. (2018)

21. S. Acharki, Apports de la modélisation et de la télédétection dans l'étude de l'impact des changements climatiques sur les ressources en eau : Application aux périmètres irrigués du Loukkos et du Gharb (Maroc), PhD thesis, University of Abdelmalek Essaadi, 190 (2020)

22. K. Khomsi, G. Mahe, Y. Tramblay, M. Sinan, M. Snoussi, Regional impacts of global change: seasonal trends in extreme rainfall, runoff and temperature in two contrasting regions of morocco, Nat. Hazards. Earth. Syst. Sci, 16 (2016)

23. A. Amengual, V. Homar, R. Romero, S. Alonso, C. Ramis, A statistical adjustment of regional climate model outputs to local scales: application to Platja de Palma, Spain. J. Clim, 25 (2012)

24. T. Jaw, J. Li, K.I. Hsu, S. Sorooshian, F. Driouech, Evaluation for Moroccan dynamically downscaled precipitation from GCM CHAM5 and its regional hydrologic response, J. Hydrol, Regional Studies, 3, 359-378 (2015)
25. Y. Brouziyne, A. Abouabdillahb, A. Hirichc, R. Bouabidb, R. Zaaboulc, L. Benaabidatea, Modeling sustainable adaptation strategies toward a climatesmart agriculture in a Mediterranean watershed under projected climate change scenarios, Agris. Syst, 162, 154-163 (2020)

26. Y. Brouziyne, A. Abouabdillahb, A. Chehbouni, L. Hanich, Assessing Hydrological Vulnerability to Future Droughts in a Mediterranean Watershed: Combined Indices-Based and Distributed Modeling Approaches, Water, 12(2333) (2020)

27. A. Ahbari, L. Stour, A. Agoumi, Impacts of Climate Change on the Hydro- Climatology and Performances of Bin El Ouidane Reservoir: Morocco, Africa, AHCCA, Springer. Cham, 23 (2021) 